\title{
Advancing the Design of Self-Explanation Prompts for Complex Problem-Solving
}

\author{
Hyun Joo \\ Korea Institute of Human Resources Development in Science and Technology, \\ Chungcheongbukdo, Republic of Korea \\ https:// orcid.org/0000-0001-5460-2988 \\ Jinju Lee \\ Hanyang University, Seoul, Republic of Korea \\ https://orcid.org/0000-0002-2958-659X \\ Dongsik Kim \\ Hanyang University, Seoul, Republic of Korea \\ https://orcid.org/0000-0001-5112-7392
}

\begin{abstract}
This research investigated the effects of focus (inference vs. inference followed by integration) and level (low vs. middle vs. high) in self-explanation prompts on both cognitive load and learning outcomes. To achieve this goal, a $2 * 3$ experiment design was employed. A total of 199 South Korean high school students were randomly assigned to one of six conditions. The two-way MANOVA was used to analyse the effects of the self-explanation prompts on learning outcomes. Results showed that there was an interaction effect between focus and level of self-explanation prompts on delayed conceptual knowledge, suggesting that the focus of self-explanation prompts could be varied depending on their level. Second, learners who were given a high level of prompts scored higher on the immediate conceptual knowledge test than those who received a low level of prompts. A two-way ANOVA was conducted to analyse the effects of the self-explanation prompts on cognitive load and showed no significant interaction effect. However, there was a main effect in the level of the prompt that a high level of self-explanation prompts imposed a lower cognitive load compared to a low level of prompts. In sum, the design and development of self-explanation prompts should consider both focus and level, especially to improve complex problem-solving skills.
\end{abstract}

Keywords: cognitive load; complex problem-solving; conceptual knowledge; procedural knowledge; self-explanation prompts 


\section{Introduction}

Self-explanation and its effect on learning outcomes has been explored extensively; learners can generate fruitful outcomes when they devise their own explanations to understand the principles of they are learning (Chi, de Leeuw, Chiu, \& LaVancher, 1994; Miller-Cotto \& Auxter, 2019). In fact, many empirical studies have demonstrated an improvement in transfer performance among students who were frequently prompted to self-explain learning materials, as compared to those who were not (Renkl \& Eitel, 2019). However, according to self-explanation meta-analysis results (Bisra, Liu, Nesbit, Salimi \& Winne, 2018), outcomes of self-explanation were critically associated with the formats, types, and timing of eliciting events. Numerous studies have confirmed that certain types of prompts could be more effective than others in different contexts for a variety of domains and tasks, suggesting the types of prompts needed for specific areas of learning (Nokes, Hausmann, VanLehn \& Gershman, 2011). In this regard, the present paper attempted to investigate how types of self-explanation prompt differently affect learning with respect to two main issues, focus and level of prompts, and provide insight in designing self-explanation prompts.

\section{Literature review}

\subsection{Effects of self-explanation prompts in learning}

Hefter and Berthold (2020) examined the productivity of self-explanation activities in learning and extended their scope to instructional supports that foster participation in an activity and make it more powerful. Providing self-explanation prompts that support the generation of self-explanation has been explored in several studies (e.g., Atkinson, Renkl \& Merrill, 2003; Lin \& Atkinson, 2013). Prompts that refer to questions or elicitations that provide instructional hints to induce meaningful learning in self-explanation have also been explored (Johnson \& Mayer, 2010).

\subsubsection{Self-explanation prompts and acquisition of conceptual and procedural knowledge} Conceptual knowledge refers to the factual knowledge and basic principles that are applied to a certain domain while "Procedural knowledge (problem-solving performance) refers to actions or manipulations that are valid within a domain" (de Jong \& Ferguson-Hessler, 1996, p. 107). The acquisition of conceptual knowledge enables the effective use of procedural knowledge in problem-solving (McCormick, 1997). These two types of knowledge greatly influence the problemsolving mechanism. Becoming equipped with a highly systemized set of knowledge (e.g. economics, mathematics) enables learners to systematically solve problems in different situations. Learners can only gain this ability when the core concepts of a problem and solutions to it are completely understood as both conceptual and procedural knowledge required to solve a problem (RittleJohnson \& Schneider, 2015).

Inducing learners to engage in self-explanation through prompts enhances both conceptual and procedural knowledge (Berthold, Eysink \& Renkl, 2009; Durkin \& Rittle-Johnson, 2012). In the case of conceptual knowledge, students can repair and enrich their existing knowledge to create a better structure by focusing on relevant concepts that explain what was learned (Fonseca \& Chi, 2010; Renkl, 
2014). The act of self-explaining spontaneously facilitates the understanding of rules and principles to make problem-solving easier and promotes procedural knowledge acquisition (Atkinson et al., 2003; Lombrozo, 2006). Especially, under complex learning circumstances, prompts that attract learners' attention to certain aspects impede deeper processing of other important aspects (Berthold, Röder, Knorzer, Kessler \& Renkl, 2011).

The instructional fit hypothesis states that the effect of self-explanation prompts is more powerful when the objective of the prompt matches both the structure of the learning domain and the learner's state of cognitive processing (Nokes et al., 2011). Thus, prompts must be designed to facilitate development of both procedural and conceptual knowledge for solving complex problems. The current study explored ways to design the focus and level of self-explanation prompts in economics lessons to enhance procedural and conceptual learning outcomes.

\subsubsection{Self-explanation prompts for managing cognitive load}

Cognitive load theory (CLT) states that the capacity and duration of working memory are limited (Sweller, Ayres \& Kalyga, 2011), and this hypothesis has been regarded as a keystone in instructional design. To avoid learning impairment, working memory should not be overloaded by cognitive processes such as comprehension, schema construction, and problem-solving (Ginns \& Leppink, 2019). Cognitive load is the sum of three load types: intrinsic, germane, and extraneous (Sweller et al., 2011). Intrinsic load is generated by task complexity and the learner's prior knowledge (knowledge state) of the subject; it must be managed through an instructional design that carefully balances learning tasks and prior knowledge (Kalyuga, Ayres, Chandler \& Sweller, 2003). Extraneous load is the additional effort that learners must put into completing poorly designed tasks or receiving poorly designed instruction (Sweller et al., 2011). Germane load piles up when cognitive processes are stimulated by instructions assumed to be beneficial for learning (Sweller et al., 2011).

Given these cognitive mechanisms, self-explanation prompts can be a doubleedged sword. Providing additional self-explanation, especially for novice learners, is extraneous and increases cognitive load (Hoogerheide, Deijkers, Loyens, Heijltjes \& van Gog, 2016). Yet, such extra cognitive activity "directly contributes to [the] schema construction" (Renkl \& Atkinson, 2003, p. 17) involved in self-explanation, such as generating inferences, integrating new information with prior knowledge, and rectifying faulty knowledge (Roy \& Chi, 2005). These processes inversely decrease intrinsic cognitive load because the elements of information-to-be-learned become a chunked schema (Paas \& Ayres, 2014). Moreover, the combination of self-explanation prompts and adequate instruction can compensate for induced extraneous overload (Wang \& Adesope, 2017). In short, learners may benefit from the germane cognitive processes of selfexplanation prompts, as the activity itself boosts the process, and the other cognitive load sub-categories allow extra space for the germane process (Leppink, Broers, Imbos, van der Vleuten \& Berger, 2012). Yet, studying and solving complex problems requires increased working memory resources, leaving fewer 
for self-explanation. Therefore, the design of self-explanation prompts should not increase cognitive load beyond the working memory capacity of learners.

\subsection{Design considerations for self-explanation prompts}

Exploratory studies of self-explanation prompts have investigated two main areas: (1) focus of prompts - effect of prompt type on self-explanation (e.g., Nokes et al., 2011; Renkl, 2014; Yeh, Chen, Hung, \& Hwang, 2010) and (2) level of prompts - how much prompting is necessary to elicit self-explanation (e.g., Berthold et al., 2009; Fabic, Mitrovic \& Neshatian, 2019; Rau, Aleven \& Rummel, 2015; Wylie \& Chi, 2014). These two research streams share similarities with research on prompts in the form of questions or hints (instructional assistance) that are designed to induce the learner's engagement in productive learning processes and avoid shallow information-processing (e.g., King, 1990). The ideal design of prompts that induce self-explanation considers both the content and number of prompts a learner needs.

\subsubsection{The focus of self-explanation prompts}

It is necessary to understand how self-explanation improves learning outcomes to intelligently design self-explanation prompts (Neubrand \& Harms, 2017; Yeh et al., 2010). There are two primary ways in which self-explanation promotes learning (Chi, 2000; Rittle-Johnson, Loehr \& Durkin, 2017). First, self-explanation encourages learners to generate inferences about what they have learned but do not yet fully understand, allowing them to identify and fill-in gaps in their knowledge (Gadgil, Nokes-Malach \& Chi, 2012). Second, recent studies have found that self-explanation can be utilized for the correlation of existing mental models with new information, supporting the establishment of a new mental model for problem-solving (Lombrozo, 2006). For instance, explanations often integrate different pieces of new information or prior knowledge with new information. Studies of these approaches highlight that explanation prompts focussing on one aspect of the to-be-learned materials have an impact on the explanation content.

Studies on the effects of self-explanation prompts on conceptual and procedural knowledge acquisition have mixed findings. DeCaro and Rittle-Johnson (2012) showed that prompts had a negative effect on procedural knowledge, yet fostered conceptual understanding. McEldoon, Durkin and Rittle-Johnson (2013) reported that prompts improved both knowledge types. Self-explanation itself is a conceptual-oriented activity, and the effects of prompts on learning outcomes vary by learning domain and the problem's complexity (Berthold \& Renkl, 2009).

Based on previous findings, supporting self-explanation activities for complex problems by designing and providing prompts could foster better learning outcomes and optimize cognitive load (i.e., reduce extraneous load while stimulating germane load) (Hefter \& Berthold, 2020; Lin, Atkinson, Savenye \& Nelson, 2016). Inference-based prompts are expected to assist the acquisition of initial problem-solving schemas in the early learning phases. By linking general concepts and skills to the specific elements of the problem at hand through inferences, learners increase their understanding (Rau et al., 2015). As learning progresses and learners understand new information, they go through an 
integrated process that links, distinguishes, organizes, and structures all the information they have learned (Morrison, Bol, Ross \& Watson, 2015). This process is essential for problem-solving (Jonassen, 2000): by coordinating external information and existing knowledge, integration leads to better understanding (Wittrock, 1989). The integration-based prompt, an inference-generating prompt designed to stimulate learners to compare and revise knowledge they acquired in the preceding learning phase with the current learning phase, can help learners solve complex problems.

\subsubsection{The assisting level of self-explanation prompts}

Not all self-explanation enhances learning outcomes, however, as learners are often ignorant about the ways to engage in productive self-explanation (Chi, 2000). Indeed, self-explanation can place a heavy burden on working memory, particularly that of learners with less relevant knowledge (Barbieri, Miller-Cotto \& Booth, 2019). For this reason, to participate in effective self-explanation, learners may need scaffolding for prompts ( $\mathrm{O}^{\prime}$ Neil, Chung, Kerr, Vendlinski, Buschang \& Mayer, 2014; Rau et al., 2015).

A scaffolded self-explanation approach is structured prompting that improves the quality of self-explanations (Chen, Mitrovic \& Matthews, 2019; Rittle-Johnson, Loehr \& Durkin, 2017). Unlike open prompts, structured prompts include additional information such as cues for selection of appropriate explanations among various choices or fill-in-the-blanks. However, withholding cues may be appropriate for constructive learning activities such as inference creation as it helps learners understand problem solutions through self-generated explanations (De Koning, Tabbers, Rikers \& Paas, 2011;). These explanations take advantage of the fact that structured prompts do not limit or influence learners with preconceived ideas (Dunlosky, Rawson, Marsh, Nathan \& Willingham, 2013; Fiorella \& Mayer, 2015). Chiu and Chi (2014) similarly found that learners provided with the support of varying levels of self-explanation prompts generate optimal selfexplanations.

According to Rittle-Johnson, Loehr and Durkin's (2017) meta review on selfexplanation prompts, the effect size for scaffolded and structured self-explanation prompts studies was larger compared to non-scaffolded prompts studies for conceptual knowledge, indicating that structured scaffolding improved the effectiveness of self-explanation in acquiring conceptual knowledge $(\beta=0.67, p=$ $0.004)$. However, providing scaffolding in prompts did not influence procedural knowledge acquisition. In complex problem-solving, the working memory resources needed for processing conceptual aspects may exceed the maximum limit of cognitive capacity, leaving no capacity for processing procedural aspects (Sweller et al., 2011). Thus, it can be inferred that if cognitive load is wellmanaged, learners may have enough capacity in the working memory for procedural aspects.

Based on this inference, Berthold et al. (2009) suggest the integration of structured and open-ended self-explanation responses. In their study, participants were provided with open prompts, assisted prompts that required learners to fill in 
blanks followed by open prompts, or no prompts at all. Though both prompt types equally affected the acquisition of procedural knowledge, assisted prompts led to better conceptual knowledge acquisition than open prompts. Thus, when students have difficulty answering open-ended questions, scaffolding and assistance in self-explanation produces deeper understanding.

Sweller et al. (2011) imply that there is a fading effect in cognitive load theory, which means that there should be a gradual decrease in the level of instructional guidance that accompanies the gradual increase in learner expertise. As learners increase their self-explanation skills or they enter later learning phases, high-level prompting needs to be reduced as minimal guidance could be more effective than explicit guidance that induces extraneous load.

This study managed the level of prompting provided to learners by drawing on previous studies (Berthold et al., 2009; Wylie \& Chi, 2014). Thus, it was expected that high levels of self-explanation prompts would be more beneficial for constructing knowledge than low levels of self-explanation prompts due to the characteristics of economics, a complex field of conceptual and procedural knowledge, which was the knowledge domain used in this study. Working on complex tasks without any assistance from self-explanation prompts is much more difficult for learners when outlining semantic knowledge (Berthold et al., 2009). Previous studies provided learners with specific assistance for generating self-explanations by requiring them to complete fill-in-the-blank exercises; however, this study aimed to provide learners with more generic prompts that provided lower levels of assistance by giving keywords with an open-ended question followed by open-ended question prompts.

\subsection{Research questions}

Studies have examined how the focus or level of assistance provided by selfexplanation prompts can affect learning outcomes, but there have been relatively few studies on the combination of these two factors. Therefore, the objective of this research was to design and implement self-explanation prompts with different combinations of focus and level of assistance to determine how they affect cognitive load, conceptual knowledge acquisition, and procedural knowledge acquisition. The study sought to answer the following research questions:

- To what extent do the focus (inference vs. inference followed by integration) and the level (low vs. middle vs. high) of self-explanation prompts affect procedural knowledge (immediate and delayed test)?

- To what extent do the focus (inference vs. inference followed by integration) and the level (low vs. middle vs. high) of self-explanation prompts affect conceptual knowledge (immediate and delayed test)?

- To what extent do the focus (inference vs. inference followed by integration) and the level (low vs. middle vs. high) of self-explanation prompts affect cognitive load? 


\section{Methodology}

\subsection{Participants and research design}

This study was conducted in a high school in Suwon, South Korea. The participants were $233 \mathrm{~K}-10$ students (female $=52 \%$, male $=48 \%$; average age $=15.8$ ) who had learned about exchange rates from their curriculum. The experiment was divided into two sessions. The first session comprised pretest, learning phase, and immediate test. A week later, there was a second session comprising a delayed test. There were 19 participants who were not able to finish the learning task, and 15 participants were absent for the delayed test. As a result, data from 199 students were used for the analyses.

A 2x3 experimental design was used with two factors. The first was the focus of self-explanation prompts - inference (' $\mathrm{IF}^{\prime}$ ) and inference-generating followed by integration ('IT'). The second was the level of self-explanation prompts - low level of self-explanation prompts that only had open-ended questions ('L'), middle level of self-explanation prompts that included an open-ended question with keywords followed by open-ended questions (' $\left.\mathrm{M}^{\prime}\right)$, and high level of selfexplanation prompts with fill-in-the-blank questions followed by an open-ended question $\left({ }^{\prime} \mathrm{H}^{\prime}\right)$. Participants were randomly assigned to one of six conditions: IF-L $(n=32)$, IT-L $(n=38)$, IF-M $(n=36)$, IT-M $(n=38)$, IF-H $(n=29)$, and IT-H $(n=26)$. The number of participants for each condition varied due to missing data. This variance does not hinder statistical validity, as the group number is regarded as approximately equal if the ratio of largest group to smallest group is less than 1.5 (Hahs-Vaughn, 2017).

\subsection{Learning materials}

\subsubsection{Development of compounds in learning materials}

The first and second author and two economic teachers with 3 to 5 years of experience developed experimental materials based on previous research (e.g., van Gog, Paas \& Van Merriënboer, 2004). The lesson included in the material was the effects of exchange rate fluctuations on the economy in social science disciplines. All learning materials were on paper. Process-oriented worked examples were employed as the learning strategy, as they use relatively little working memory (van Gog et al., 2004).

The study used three example problems in order of incremental complexity. The problems were intended to show how to examine the economic impact of exchange rate fluctuations, and the problem statement of the research was: 'Analyse the profit and loss of export and import companies due to exchange rate fluctuations'. To solve the problems, a learner first needs to understand that the domestic economic environment and foreign exchange market status affect exchange rate fluctuations; export management conditions; and dynamics of exporting/importing companies. This means that a learner must coordinate multiple informational elements. Moreover, this study examined a specific domain of macroeconomics, the impact of exchange fluctuations, which required the use of both conceptual and procedural knowledge in the application of economic principles to solve domestic economic and/or foreign exchange market analysis. 
The three learning tasks with incremental complexity levels were as follows. Learning task 1 (simple): 'Predict changes in international currency exchanges from an analysis of the domestic economy'. Learning task 2 (medium): 'Analyse the impact of exchange rate fluctuations on an export company'. Learning task 3 (complex): 'Analyse and evaluate an import company's financial losses from exchange rate fluctuations'. The answers to all three learning tasks including detailed explanations (procedural and conceptual knowledge) provided to the students for each of the logical processes (Figure 1). When continuously presented with worked examples, these become redundant information and interfere with leaners' constructive activities, inducing extraneous load (redundancy effect in CLT; Sweller et al., 2011). Thus, the solution step was omitted from the examples to execute the fading strategy (e.g., Atkinson et al., 2003).

\begin{tabular}{ccccc} 
& & & & \\
& & Learning task 1 & Learning task 2 & $\begin{array}{c}\text { increasing complexity } \\
\text { Learning task 3 }\end{array}$ \\
Focus & Inference(IF) & Generate inferencing & Generate inferencing & Generate inferencing \\
\cline { 2 - 5 } & Integration(IT) & Generate inferencing & Generate inferencing & Integration \\
\cline { 2 - 5 } Level & Low (L) & Open question & Open question & Open question \\
\hline & Middle (M) & Open question with keyword & Open question with keyword & Open-ended question \\
\hline & High (H) & Fill-in-the-blank & Fill-in-the-blank & Open-ended question
\end{tabular}

Figure 1: Description of learning materials

\subsubsection{Self-explanation prompts embedded in learning materials}

The prompts were given in place of the solution step, and the students were asked to answer prompts for each example. In this study, all prompts were revised and adapted from previous research. The 'IF' prompt corresponds to the one in Conati and VanLehn (2000), and focused on generating inferences to fill the gaps (e.g., 'The answer is correct because...' or 'What is the justification for this process? Why do you think it is correct?'). The 'IT' prompt was adapted from Chi et al. (1994) and was designed to facilitate an integration between prior knowledge and new information (e.g., 'How does it relate to what you have already seen?' or 'What kind of new information does each step provide for you?'). Specifically, IT prompts provide an extra opportunity to first engage in self-explanation activities through comparison with information from previous steps, and second, to revise learners' initial ideas by presenting correct answers. The ' $L$ ' prompt was an openended question for all learning tasks, and the ' $\mathrm{M}$ ' prompt was again an openended question but with keywords for learning tasks 1 and 2, and with a few more open-ended questions for 3 . The ' $\mathrm{H}^{\prime}$ prompt was the same as the one used by Berthold et al. (2009) and consisted of a fill-in-the-blank question for learning tasks 1 and 2, and an open-ended question for 3. More specifically, prompts in this study can be specifically tailored to the learning context (Figure 2).

\subsection{Procedures and instrument}

\subsubsection{Procedures}

Two sessions were conducted. In the first session, participants were given 10 minutes to complete a pretest followed by the learning phase and an immediate posttest. During the learning phase, participants were asked to study three problems and provided with process-oriented worked examples. They then completed their respective self-explanation activities by using sets of assigned 
prompts. They were given 20 minutes to solve and self-explain each problem. At the end of the learning phase, they were asked to rate the mental effort they had invested via a self-reported questionnaire and were given 15 minutes to complete the immediate posttest. The second session was held a week later in which all groups were given 15 minutes to take a delayed posttest (see Table 1 for details).

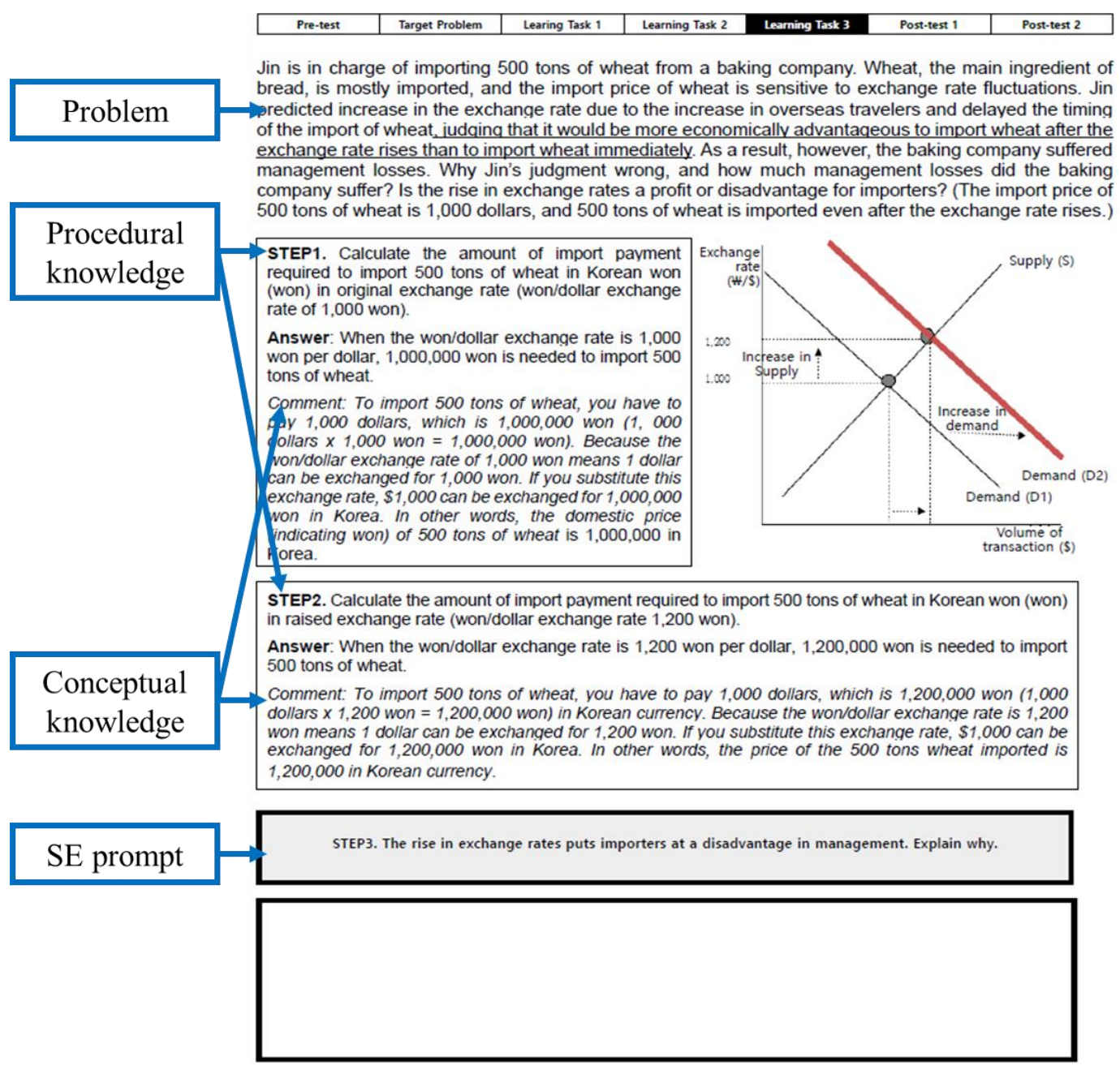

Figure 2: Example of learning tasks in the IF-H condition

Table 1: Experiment procedures

\begin{tabular}{|c|c|c|}
\hline Session & Activity & Details \\
\hline \multirow{3}{*}{$\begin{array}{l}\text { First session } \\
\left(1^{\text {st }} \text { week }\right)\end{array}$} & Pretest (10 min) & 12 items measuring prior knowledge \\
\hline & $\begin{array}{l}\text { Learning phase } \\
(60 \mathrm{~min})\end{array}$ & $\begin{array}{l}\text { Problem with worked examples }+ \\
\text { self-explanation activity }(20 \mathrm{~min} * 3 \text { problem sets })\end{array}$ \\
\hline & $\begin{array}{l}\text { Immediate posttest } \\
(15 \mathrm{~min})\end{array}$ & Mental effort rating \\
\hline $\begin{array}{l}\text { Second session } \\
\left(2^{\text {nd }} \text { week }\right)\end{array}$ & $\begin{array}{l}\text { Delayed posttest } \\
(15 \mathrm{~min})\end{array}$ & Conceptual and procedural knowledge \\
\hline
\end{tabular}




\subsubsection{Pretest}

A pretest was conducted to confirm the homogeneity among the six groups by measuring their prior knowledge of the subject. The pretest contained 12 items measuring knowledge of the basic concepts of exchange rates such as, 'The KRW/USD exchange rate is the amount of US dollars that can be exchanged for 1,000 won in Korea'. The pretest was comprised of right or wrong quizzes and scored by the researcher. One point was assigned for each correct answer, hence the maximum score of the pre-test was 12 points.

\subsubsection{Post-test}

The posttests aimed to assess both procedural and conceptual knowledge and were administered immediately after the learning session and one week later.

\subsubsection{Procedural knowledge}

Participants demonstrated procedural knowledge by solving calculation problems. The immediate test consisted of 8 items including 3 short answer questions (e.g., 'Calculate the change in export value of $\$ 30,000$ when the exchange rate rises from 1,000 KRW to 1,200 KRW.'), 3 true or false questions (e.g., 'If the exchange rate, which was 1,000 KRW per USD, changes to $800 \mathrm{KRW}$ per USD, the value of the won fell to...'), and 2 multiple choice questions. The internal consistency, using Cronbach's alpha was reliable with $\sigma=.71$. The delayed test included 3 short answer questions (e.g.,' Analyse the graph to predict the changes in the foreign exchange rate and its impact on the fruit import business.').

\subsubsection{Conceptual knowledge}

In this research, the focus was on whether the learner understood each step of the logical process to obtain the answer. The study measured the conceptual understanding of the rationale behind the solution process. The immediate test contained 3 open-ended questions that required written explanations of the principles presented in the learning phase (e.g., 'Look at the trends in exchange rates and write down reasons why certain trends would be favourable to exporters and/or importers.') (Cohen's $\mathrm{K}=.82$ ). The delayed test included 5 openended questions similar to the immediate test (e.g., 'Interpret the changes in graphs and exchange rates and state your expectations of their impact on the economy with reasons.') (Cohen's K=.81).

\subsubsection{Cognitive load}

The learners' perceived cognitive loads were measured via a self-reported questionnaire developed by Paas and van Merriënboer (1994). The questionnaire consisted of a nine-point Likert-scale, ranging from 'extremely easy' (1) to 'extremely difficult' (9) (Figure 3). The questionnaire was handed out immediately after the task class session. The internal consistency coefficient of the scale (Cronbach's o) was .90. 
Check one of the nine-point scales below, from "It was very easy" to "It was very difficult".

\begin{tabular}{|c|c|c|c|c|c|c|c|c|}
\hline 1 & 2 & 3 & 4 & 5 & 6 & 7 & 8 & 9 \\
\hline
\end{tabular}

Figure 3: Self-reported cognitive load questionnaire

\section{Results and Discussion}

\subsection{Results}

\subsubsection{Prior knowledge}

A one-way analysis of variance (ANOVA) was conducted to evaluate whether participants' prior knowledge significantly differed across the six experimental conditions. The homogeneity in prior knowledge among groups was confirmed since there was no significant difference in pretest scores $(\mathrm{F}(5,193)=1.66, p=.147)$.

\subsubsection{Learning outcomes}

We expected that integration-based prompts with middle or high level of prompts would benefit learners most when studying a complex problem. This hypothesis was partially confirmed for conceptual understanding but not for procedural knowledge. Means and standard deviations of learning outcomes are presented in Table 2.

Table 2: Means and standard deviations of learning outcomes by groups

\begin{tabular}{|l|c|c|c|c|c|c|c|c|c|c|c|c|}
\hline \multirow{2}{*}{ Aspect } & \multicolumn{2}{|c|}{$\begin{array}{c}\text { IF-L } \\
(\mathrm{n}=32)\end{array}$} & \multicolumn{2}{c|}{$\begin{array}{c}\text { IT-L } \\
(\mathrm{n}=38)\end{array}$} & \multicolumn{2}{c|}{$\begin{array}{c}\text { IF-M } \\
(\mathrm{n}=36)\end{array}$} & \multicolumn{2}{c|}{$\begin{array}{c}\text { IT-M } \\
(\mathrm{n}=38)\end{array}$} & \multicolumn{2}{c|}{$\begin{array}{c}\text { IF-H } \\
(\mathrm{n}=29)\end{array}$} & \multicolumn{2}{c|}{$\begin{array}{c}\text { IT-H } \\
(\mathrm{n}=26)\end{array}$} \\
\cline { 2 - 14 } & $\mathrm{M}$ & $\mathrm{SD}$ & $\mathrm{M}$ & $\mathrm{SD}$ & $\mathrm{M}$ & $\mathrm{SD}$ & $\mathrm{M}$ & $\mathrm{SD}$ & $\mathrm{M}$ & $\mathrm{SD}$ & $\mathrm{M}$ & SD \\
\hline I_pro & 5.59 & 1.98 & 5.05 & 2.55 & 4.50 & 2.15 & 5.11 & 2.39 & 5.31 & 2.48 & 5.46 & 1.77 \\
\hline D_pro & 4.31 & 1.85 & 4.18 & 2.15 & 3.08 & 2.43 & 4.11 & 2.02 & 4.14 & 2.03 & 4.38 & 2.11 \\
\hline I_con & 4.63 & 3.79 & 4.00 & 3.40 & 4.64 & 3.21 & 6.61 & 2.99 & 5.24 & 3.42 & 6.42 & 3.24 \\
\hline D_con & 7.22 & 3.41 & 8.76 & 3.92 & 7.53 & 4.16 & 9.05 & 3.30 & 9.76 & 3.33 & 7.23 & 2.93 \\
\hline
\end{tabular}

Note. I_pro: immediate procedural knowledge; D_pro: delayed procedural knowledge; I_con: immediate conceptual knowledge, D_con: delayed conceptual knowledge

A $2 \times 3$ MANOVA was conducted to examine the effects of self-explanation prompts' focus and level, as well as the interactive effect of self-explanation prompts' focus and level on learning outcomes. Box's M Test for homogeneity of covariance matrices was met (Box's M=55.52, F=1.05, $p=.377$ ). Levene's Test, the 
assumption of equal variance, was met at the .05 alpha level ( $p$ ranged from .355 to .915), except for immediate procedural knowledge $(p=.031)$. Utilizing Pillai's Trace, as shown in Table 3 , the interaction effect was significant (Pillai's Trace $\left.=.137, \mathrm{~F}(8,382)=3.51, p=.001, \eta_{p}{ }^{2}=.068\right)$; the main effect of the self-explanation prompts' level was also significant (Pillai's Trace $=.102, \mathrm{~F}(8,382)=2.557, p=.010 \eta_{p}{ }^{2}$ $=.051)$. However, as shown in Table 3 , the main effect of focus of self-explanation prompts was not significant (Pillai's Trace $=.02, \mathrm{~F}(4,190)=1.09, p=.361, \eta_{p}{ }^{2}=.022$ ).

Table 3: Two-way MANOVA and follow ANOVA summary on learning outcomes

\begin{tabular}{|c|c|c|c|c|c|c|c|c|}
\hline $\begin{array}{l}\text { Pillai's } \\
\text { Trace }\end{array}$ & Sources & Aspects & $\begin{array}{l}\text { Type III } \\
\text { sum of } \\
\text { squares }\end{array}$ & df & $\begin{array}{l}\text { Mean } \\
\text { square }\end{array}$ & $F$ & $p$ & $\eta_{p}^{2}$ \\
\hline \multirow[t]{4}{*}{.022} & \multirow[t]{4}{*}{ Focus } & I_pro & .25 & 1 & .25 & .049 & .83 & .00 \\
\hline & & D_pro & 7.04 & 1 & 7.04 & 1.57 & .21 & .01 \\
\hline & & I_con & 34.48 & 1 & 34.48 & 3.09 & .08 & .02 \\
\hline & & D_con & 1.59 & 1 & 1.59 & .12 & .73 & .00 \\
\hline \multirow[t]{4}{*}{$.102^{*}$} & \multirow[t]{4}{*}{ Level } & I_pro & 14.06 & 2 & 7.03 & 1.38 & .26 & .02 \\
\hline & & D_pro & 20.19 & 2 & 10.09 & 2.25 & .11 & .02 \\
\hline & & I_con & 89.73 & 2 & 44.87 & 4.02 & $.02 *$ & .04 \\
\hline & & D_con & 8.05 & 2 & 4.03 & .32 & .73 & .00 \\
\hline \multirow[t]{4}{*}{$.137^{* *}$} & \multirow{4}{*}{$\begin{array}{l}\text { Focus* } \\
\text { Level }\end{array}$} & I_pro & 11.87 & 2 & 5.94 & 1.16 & .32 & .01 \\
\hline & & D_pro & 12.32 & 2 & 6.16 & 1.38 & .26 & .01 \\
\hline & & I_con & 62.34 & 2 & 31.17 & 2.79 & .07 & .03 \\
\hline & & D_con & 163.66 & 2 & 81.83 & 6.40 & $.00 *$ & .06 \\
\hline & \multirow[t]{4}{*}{ Error } & I_pro & 986.86 & 193 & 5.11 & & & \\
\hline & & D_pro & 864.517 & 193 & 4.479 & & & \\
\hline & & I_con & 2156.541 & 193 & 11.174 & & & \\
\hline & & D_con & 2469.130 & 193 & 12.793 & & & \\
\hline
\end{tabular}

Note. ${ }^{*} p<.05,{ }^{* *} p<.01,{ }^{* * *} p<.001$. I_pro: Immediate procedural knowledge; D_pro: Delayed procedural knowledge; I_con: immediate conceptual knowledge, D_con: delayed conceptual knowledge

Effects on procedural knowledge For immediate procedural knowledge, subsequent univariate ANOVAs yielded that the main effect of the level of self-explanation was not significant $\left(\mathrm{F}(2,193)=1.38, p=.255, \eta_{p}{ }^{2}=.014\right)$, and was non-significant on delayed procedural knowledge $\left(\mathrm{F}(2,193)=2.25, p=.108, \mathrm{\eta}_{p}{ }^{2}=.02\right)$. There was also no interaction between focus and level of self-explanation on immediate and delayed procedural knowledge $\left(\mathrm{F}(2,193)=1.16, p=.315, \eta_{p}{ }^{2}=.012, \mathrm{~F}(2,193)=1.36, p=.255\right.$, $\eta_{p}{ }^{2}=.014$, respectively). 
Effects on conceptual knowledge For immediate conceptual knowledge, subsequent univariate ANOVAs revealed that the main effect of the level of self-explanation prompts was significant $\left(\mathrm{F}(2,193)=4.015, p=.020, \eta_{p}{ }^{2}=.040\right)$. The results of post hoc test are presented in Table 4 . However, there was no interaction effect on immediate conceptual knowledge $\left(\mathrm{F}(2,193)=2.79, p=.064, \eta_{p}{ }^{2}=.028\right)$. For delayed conceptual knowledge, there was no main effect of the level of self-explanation prompts $\left(\mathrm{F}(2,193)=.315, p=.730, \eta_{p}{ }^{2}=.003\right)$. However, there was an interaction between focus and level of self-explanation prompts $(F(2,193)=6.40, p=.002$, $\left.\eta_{p}{ }^{2}=.062\right)$, as shown in Figure 4.

Table 4: Multiple comparison using Scheffe's post hoc test

\begin{tabular}{|c|c|c|c|c|}
\hline \multirow{2}{*}{$\begin{array}{c}\text { Dependent } \\
\text { Variable }\end{array}$} & $\begin{array}{c}\text { (I) } \\
\text { Level of } \\
\text { prompts }\end{array}$ & $\begin{array}{c}\text { (J) Level of } \\
\text { prompts }\end{array}$ & $\begin{array}{c}\text { Mean difference } \\
\text { (I-J) }\end{array}$ & $p$ \\
\hline \multirow{2}{*}{$\begin{array}{c}\text { Immediate } \\
\text { conceptual } \\
\text { knowledge }\end{array}$} & $\operatorname{High}(\mathrm{H})$ & $\operatorname{Low}(\mathrm{L})$ & 1.51 & .045 \\
\cline { 2 - 5 } & $\operatorname{Low}(\mathrm{L})$ & Middle(M) & .15 & .968 \\
\hline
\end{tabular}

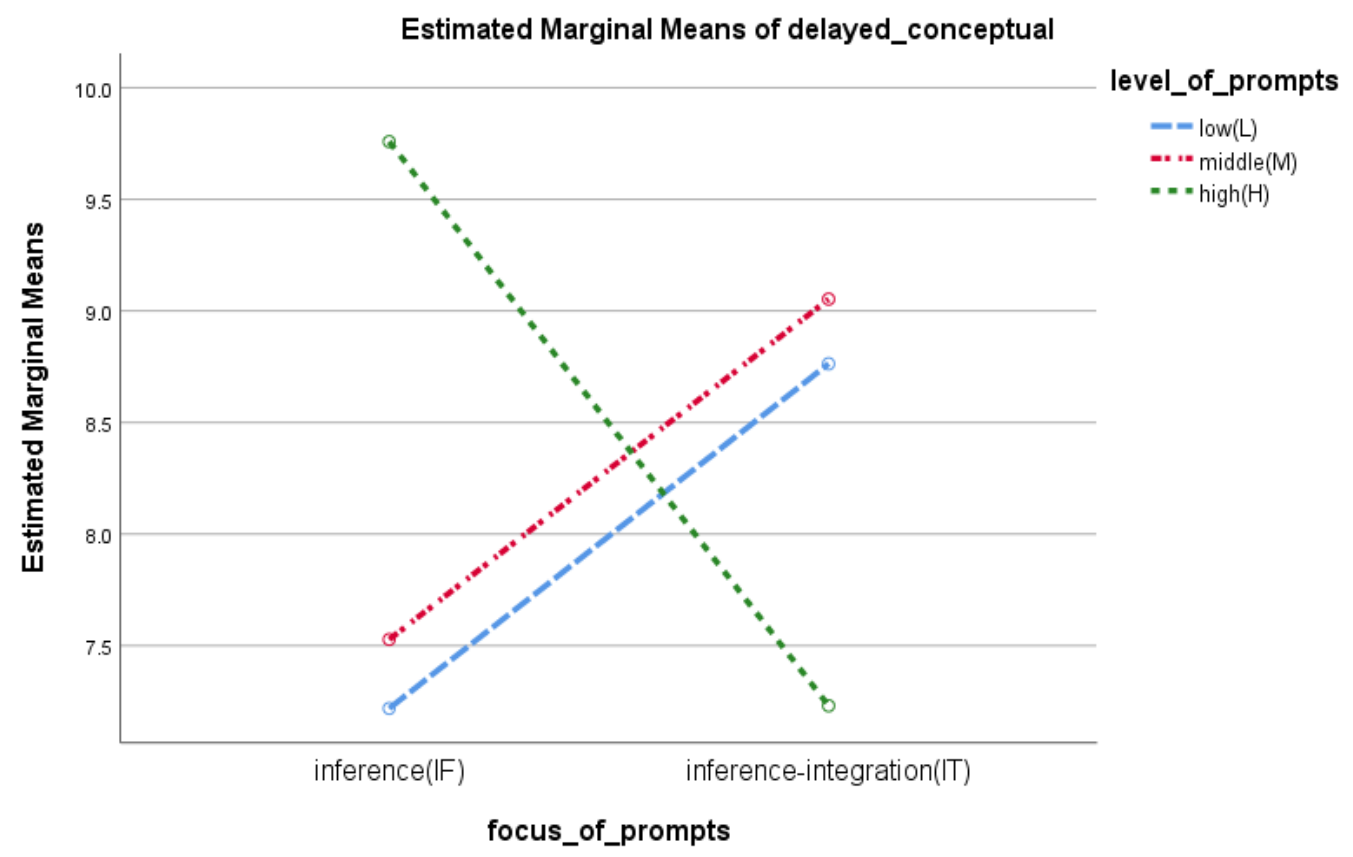

Figure 4: Interaction between focus and level of self-explanation prompts on delayed conceptual knowledge

To further understand the interaction effect of focus and level of self-explanation prompts for the aspect of delayed conceptual knowledge, the simple main effects were analysed (Table 5). Results revealed that focus of self-explanation prompts had a significant effect on delayed conceptual knowledge among the high-level $(\mathrm{H})$ prompts group $(\mathrm{F}(1,193)=6.848, p=.03)$, implying that the IF prompts group had significantly higher scores than the IT prompts group (mean difference $=2.53$, $E S(d)=1.18)$. On the other hand, the level of self-explanation prompts had a 
significant effect on delayed conceptual knowledge among learners in the IF prompts group $(\mathrm{F}(2,193)=4.550, p=.02)$, implying that the high level $(\mathrm{H})$ prompts group had significantly higher scores than the low-level (L) prompts group (mean difference=2.54, $E S(d)=1.21$ ).

Table 5: Summary of simple main effect on delayed conceptual knowledge

\begin{tabular}{|l|l|c|c|c|c|c|}
\hline \multirow{2}{*}{ Group } & Sources & $\begin{array}{c}\text { Sum of } \\
\text { squares }\end{array}$ & $\begin{array}{c}\text { Degree of } \\
\text { freedom }\end{array}$ & $\begin{array}{c}\text { Mean } \\
\text { square }\end{array}$ & F & $p$ \\
\hline \multirow{3}{*}{ Focus } & Low & 41.43 & 1 & 41.43 & 3.23 & .21 \\
\cline { 2 - 7 } & Middle & 42.98 & 1 & 42.98 & 3.36 & .21 \\
\cline { 2 - 8 } & High & 87.60 & 1 & 87.60 & 6.85 & $.03^{*}$ \\
\hline \multirow{2}{*}{ Level } & Inference & 116.41 & 2 & 58.21 & 4.55 & $.02^{*}$ \\
\cline { 2 - 8 } & Integration & 56.08 & 2 & 28.04 & 2.20 & .22 \\
\hline \multirow{2}{*}{ Error } & & 2469.13 & 193 & 12.79 & & \\
\hline
\end{tabular}

Note. ${ }^{*} p<.05$

\subsubsection{Cognitive load invested for learning}

Our expectation regarding cognitive load was that integration with the assisting condition (high and middle level prompts) would lead to less cognitive load during studying. Means and standard deviations of the cognitive load when studying are presented in Table 6.

A $2 \times 3$ ANOVA was conducted to examine the effects of focus and level of selfexplanation prompts on cognitive load. The homogeneity assumption was sustained $(F(2,193)=2.17, p=0.059)$. Results revealed a non-significant two-way interaction $\left(\mathrm{F}(2,193)=.68, p=.511, \eta_{p}{ }^{2}=.007\right)$. The main effect of self-explanation prompts' focus on cognitive load was also not significant $(\mathrm{F}(1,193)=2.452, p=.119$, $\left.\eta_{p}{ }^{2}=.013\right)$, while the main effect of level of prompts for cognitive load was significant $\left(\mathrm{F}(2,193)=13.71, p<.01, \eta_{p}^{2}=.124\right)$ (Table 7$)$. The results of post hoc test are presented in Table 8.

Table 6: Mean (SD) of cognitive load rating (range 1-9)

\begin{tabular}{|c|c|c|c|c|c|c|c|c|c|c|c|c|}
\hline \multirow{2}{*}{ Aspect } & \multicolumn{2}{|c|}{$\begin{array}{c}\text { IF-L } \\
(\mathrm{n}=32)\end{array}$} & \multicolumn{2}{|c|}{$\begin{array}{l}\text { IT-L } \\
(\mathrm{n}=38)\end{array}$} & \multicolumn{2}{|c|}{$\begin{array}{l}\text { IF-M } \\
(\mathrm{n}=36)\end{array}$} & \multicolumn{2}{|c|}{$\begin{array}{l}\text { IT-M } \\
(\mathrm{n}=38)\end{array}$} & \multicolumn{2}{|c|}{$\begin{array}{l}\text { IF-H } \\
(\mathrm{n}=29)\end{array}$} & \multicolumn{2}{|c|}{$\begin{array}{l}\text { IT-H } \\
(n=26)\end{array}$} \\
\hline & $\mathrm{M}$ & SD & $\mathrm{M}$ & SD & $\mathrm{M}$ & SD & $\mathrm{M}$ & SD & $\mathrm{M}$ & SD & $\mathrm{M}$ & SD \\
\hline $\begin{array}{l}\text { Cognitive } \\
\text { load }\end{array}$ & 7.31 & 1.36 & 7.34 & 1.67 & 6.24 & 2.17 & 6.69 & 1.57 & 5.42 & 1.92 & 6.13 & 1.86 \\
\hline
\end{tabular}


Table 7: Two-way ANOVA summary of cognitive load

\begin{tabular}{|l|c|c|c|c|c|c|}
\hline \multicolumn{1}{|c|}{ Sources } & $\begin{array}{c}\text { Sum of } \\
\text { squares }\end{array}$ & $\begin{array}{c}\text { Degree of } \\
\text { freedom }\end{array}$ & $\begin{array}{c}\text { Mean } \\
\text { square }\end{array}$ & $\mathbf{F}$ & $\boldsymbol{p}$ & $\boldsymbol{\eta}_{\boldsymbol{p}}{ }^{2}$ \\
\hline Focus & 7.74 & 1 & 7.74 & 2.45 & .12 & .01 \\
\hline Level & 86.56 & 2 & 43.28 & 13.71 & $.00^{* * *}$ & .12 \\
\hline Focus*Level & 4.25 & 2 & 2.13 & .67 & .51 & .01 \\
\hline Error & 609.37 & 193 & 3.16 & & & \\
\hline
\end{tabular}

Note. ${ }^{* * *} p<.001$

Table 8: Multiple comparison using Scheffe's post hoc test

\begin{tabular}{|c|c|c|c|c|}
\hline $\begin{array}{c}\text { Dependent } \\
\text { Variable }\end{array}$ & $\begin{array}{c}\text { (I) Level of } \\
\text { prompts }\end{array}$ & $\begin{array}{c}\text { (J) Level of } \\
\text { prompts }\end{array}$ & $\begin{array}{c}\text { Mean difference } \\
\text { (I-J) }\end{array}$ & $\boldsymbol{p}$ \\
\hline \multirow{2}{*}{ Cognitive load } & $\operatorname{High}(\mathrm{H})$ & Low(L) & -0.87 & .026 \\
\cline { 2 - 5 } & & Middle(M) & .67 & .108 \\
\cline { 2 - 5 } & Low(L) & Middle(M) & 1.54 & .000 \\
\hline
\end{tabular}

\subsection{Discussion}

\subsubsection{Effects on learning outcomes}

Prior to the study, the research hypothesis was that the most effective instructional strategy was to assist students with prompts so they could generate inferences and integrate accumulated knowledge from previous learning stages. The researchers assumed that it would suit most learners' knowledge states and learning phases, and the results partially supported this. The self-explanation prompts influenced conceptual knowledge but not procedural knowledge. In other words, the focus and level of self-explanation prompts affect learning outcomes depending on the target knowledge.

Effects on conceptual knowledge. There are three findings from the results. First, there was an interaction effect between focus and the level of self-explanation prompts, which improved the delayed conceptual knowledge test scores. Contrary to our expectations, the inference-based prompts condition (only generate inferencing) outscored the integration-based prompts condition (generating inferences followed by integration of knowledge) in the case of high level of prompts (fill-in-the-blank followed by open-ended question). With middle or low level of prompts conditions (keyword followed by open-endedquestions and only open-ended-questions), integration-based prompts were more efficient than inference-based prompts, confirming that inference-based prompts were better under the high level of prompts condition than integration-based prompts.

This can be elaborated as follows: In the initial learning phase, learners have insufficient knowledge to solve problems. They integrate new knowledge with what they already know to acquire a coherent and complete problem-solving schema. Providing sufficient instructional aids here, such as high level of prompts, 
could facilitate schema acquisition (Nokes et al., 2011; Renkl \& Eitel, 2019). Students construct high-quality mental models in the initial learning phase. Thus, as learning phases progress, comparing information and revising initial ideas according to integration-based prompts could cause cognitive overload rather than a positive learning effect. Our results found that integration-based prompts induced more cognitive load than the inference-based prompts under high level prompt conditions (see Table 5).

With integration-based prompts, learners do not need to compare or revise their knowledge; they have already constructed an eligible problem schema. Learners may also consider a gap-filling activity more useful for learning tasks with high complexity. However, when provided with low-level assistance, learners would have benefited from integration-based prompts that can help them to revise their knowledge and mental model.

Second, learners who were given assistance through prompts scored higher on the immediate conceptual knowledge test than those who received no assistance, partially validating the hypothesis. Scaffolding explanations may reinforce the effectiveness of self-explanation prompts, especially in conceptual knowledge acquisition (Berthold et al., 2011; Rittle-Johnson, Loehr \& Durkin, 2017). However, the experiment shows that only the high-level prompts condition outperformed the low-level condition, while middle-level prompts showed no significant difference. To better understand the level of prompts, the conditions manipulated in this study did not demonstrate notable changes and lack the evidence to draw conclusions regarding the level of prompts. This could be due to small differences in the levels of assistance between the two prompts groups, which the learners were unaware of.

Effects on procedural knowledge. Third, contrary to the hypothesis, the prompts level showed no significant difference on procedural knowledge. This was consistent with Berthold et al. (2009), who found no difference between the effect of openended and assisting self-explanation prompts on procedural knowledge acquisition. One potential reason is that the differences among the prompts were too small for learner perception. Moreover, no significant difference existed between the types of focus on procedural knowledge acquisition. This may be because learners could only focus on the knowledge type intentionally elicited by the self-explanation prompts. Since learners in this study were required to explain why and how exchange rate fluctuations impact the economy, they may have focused on relevant knowledge to the detriment of the procedural aspects of the knowledge.

\subsubsection{Effects on cognitive load}

Within the realm of cognitive load framework, self-explaining prompts matched to the learning phases were expected to contribute to an efficient use of extraneous load by selecting the focus of self-explaining. Further, high levels of selfexplanation prompts were anticipated to reduce extraneous load. The restraints of the intrinsic and extraneous loads were hypothesized to lead to an increase in the germane process capacity for schema construction. 
The results partially support the hypothesis and indicate that the high and middle level of self-explanation prompts imposed lower cognitive load compared to the low level prompts. The prompts' design purpose was to reduce cognitive load in solving problems and avoid being overwhelmed by the demands of problemsolving (Sweller et al., 2011). Yet, the results imply that the prompts should be designed for learners' expertise level, since the effects of instructional guidance vary by the knowledge progression of learners. Thus, at the early phase of learning, prompts should be provided with an external support for the acquisition of problem-solving schema, as learners lack prior knowledge. As learning phases progress, a learner who has already constructed problem-solving schemata may no longer need further instructional guidance; the external support (increasing the level of prompts) for a sophisticated elicitation of self-explanation can gradually fade away.

Nonetheless, unlike the assumption outlined above, the focus of self-explanation prompts did not involve cognitive load. This contrasts with Yeh et al.'s (2010) finding that detecting and amending misconceptions works better for higherknowledge learners than simply providing inference activity. One possible explanation for this is that integration-based prompts put an extra burden on learners as these ask them to complete more work in comparing and integrating the various information they have, and consequently does not help them to learn. The integration-based prompts could have increased the undesired extraneous load which offsets the effect of germane load. In sum, integration-based prompts showed no significant difference with the inference-based prompts in terms of measuring cognitive load.

\section{Conclusion}

The findings of this study have both theoretical and practical implications. Theoretically, this study sheds a new light on the past findings with regards to self-explanation prompts. This study suggests that the designing of selfexplanation prompts should consider both components, that is the focus and level of self-explanation prompts, keeping in mind that the self-explaining prompts with different focus and level have varying effects on learning outcome, especially for enhancing delayed conceptual knowledge in complex problem solving.

In a more practical sense, Rittle-Johnson, Loehr and Durkin (2017) also have suggested that more research on self-explanation is needed in classroom contexts. This research conducted in real-classroom. This research advises taking a great caution in determining which type of prompts to use and emphasizes that the effectiveness of a prompt would vary in different occasions depending on the purpose of instruction, and the nature of the task.

Three limitations of the study should be addressed in future research. First, measurements for each cognitive load type were not included; only aggregated cognitive load was measured using Paas and van Merriënboer (1994). Thus, future studies should examine the extent to which the format of the self-explaining prompt affects intrinsic, extraneous, and germane cognitive loads 
individually(Lin et al., 2016). Second, this study did not differentiate between fixed and adaptive fading self-explanation prompts, even as it advocated for integration of structured and open-ended self-explanations, which likely entail the fading effect (in CLT, see Sweller et al., 2011). Future studies should further investigate the transition point at which the learner demonstrates their understanding, as assistance is faded from structured responses in the early instruction phase to open-ended responses in the later phase(e.g., Rau et al., 2015; $\mathrm{Si}, \mathrm{Kim}, \& \mathrm{Na}, 2014)$. The final limitation is the absence of test timings during the interpretation of the findings, which should be included to better measure learning performance and persistence of learning effects.

\section{Acknowledgements}

This work was presented at the $13^{\text {th }}$ International Conference of the Learning Sciences. We thank the publications committee of the International Society of the Learning Sciences for granting the permission to publish the conference paper.

This work is supported by NRF (National Research Foundation of Korea) Grant under Global Ph.D. Fellowship Program funded by the Korean Government (NRF-2019H1A2A1074367).

\section{References}

Atkinson, R. K., Renkl, A., \& Merrill, M. M. (2003). Transitioning from studying examples to solving problems: Effects of self-explanation prompts and fading worked-out steps. Journal of Educational Psychology, 95(4), 774-783. doi:10.1037/00220663.95.4.774

Barbieri, C. A., Miller-Cotto, D., \& Booth, J. L. (2019). Lessening the load of misconceptions: Design-based principles for algebra learning. Journal of the Learning Sciences, 28(3), 381-417. doi:10.1080/10508406.2019.1573428

Berthold, K., Eysink, T. H., \& Renkl, A. (2009). Assisting self-explanation prompts are more effective than open prompts when learning with multiple representations. Instructional Science, 37(4), 345-363. doi:10.1007/s11251- 008-9051-z

Berthold, K., \& Renkl, A. (2009). Instructional aids to support a conceptual understanding of multiple representations. Journal of Educational Psychology, 101(1), 70-80. doi:10.1037/a0013247

Berthold, K., Röder, H., Knörzer, D., Kessler, W., \& Renkl, A. (2011). The double-edged effects of explanation prompts. Computers in Human Behavior, 27(1), 69-75. doi:10.1016/j.chb.2010.05.025.

Bisra, K., Liu, Q., Nesbit, J. C., Salimi, F., \& Winne, P. H. (2018). Inducing self-explanation: A meta-analysis. Educational Psychology Review, 30, 703-725. doi:10.1007/s10648018-9434-x

Chen, X., Mitrovic, A. T., \& Matthews, M. (2019). Learning from worked examples, erroneous examples and problem solving: Towards adaptive selection of learning activities. IEEE Transactions on Learning Technologies, 13(1), 135-149. doi:10.1109/TLT.2019.2896080

Chi, M. T. H. (2000). Self-explaining expository texts: The dual processes of generating inferences and repairing mental models. In R. Glaser (Ed.), Advances in Instructional Psychology (pp. 161-238). Hillsdale, NJ: Lawrence Erlbaum Associates. 
Chi, M. T. H., de Leeuw, N., Chiu, M. H., \& LaVancher, C. (1994). Eliciting selfexplanations improves understanding. Cognitive Science, 18(3), 439-477. doi:10.1016/0364-0213(94)90016-7

Chiu, J. L., \& Chi, M. T. H. (2014). Supporting self-explanation in the classroom. In V. A. Benasi, C. E. Overson, \& C. M. Hakala (Eds.), Applying Science of Learning in Education: Infusing Psychological Science into the Curriculum (pp. 91-103). Washington, DC: Division 2, American Psychological Association.

Conati, C., \& VanLehn, K. (2000). Toward computer-based support of meta-cognitive skills: A computational framework to coach self-explanation. International Journal of Artificial Intelligence in Education (IJAIED), 11, 389-415.

DeCaro, M. S., \& Rittle-Johnson, B. (2012). Exploring mathematics problems prepares children to learn from instruction. Journal of Experimental Child Psychology, 113(4), 552-568. doi:10.1016/j.jecp.2012.06.009

De Koning, B. B., Tabbers, H. K., Rikers, R. M., \& Paas, F. (2011). Attention cueing in an instructional animation: The role of presentation speed. Computers in Human Behavior, 27(1), 41-45. doi:10.1016/j.chb.2010.05.010

de Jong, T., \& Ferguson-Hessler, M. G. (1996). Types and qualities of knowledge. Educational psychologist, 31(2), 105-113. doi:10.1207/s15326985ep3102_2

Dunlosky, J., Rawson, K. A., Marsh, E. J., Nathan, M. J., \& Willingham, D. T. (2013). Improving students' learning with effective learning techniques: Promising directions from cognitive and educational psychology. Psychological Science in the Public Interest, 14(1), 4-58. doi:10.1177/1529100612453266

Durkin, K. \& Rittle-Johnson, B. (2012). The effectiveness of using incorrect examples to support learning about decimal magnitude. Learning and Instruction, 22(3), 206214. doi:10.1016/j.learninstruc.2011.11.001

Fabic, G. V. F., Mitrovic, A., \& Neshatian, K. (2019). Evaluation of Parsons problems with menu-based self-explanation prompts in a mobile python tutor. International Journal of Artificial Intelligence in Education, 29(4), 507-535. doi:10.1007/s40593-01900192-0

Fiorella, L. \& Mayer, R. E. (2015). Learning as a generative activity: Eight learning strategies that promote understanding. New York: Cambridge University Press.

Fonseca, B. A., \& Chi, M. T. H. (2010). Instruction based on self-explanation. In R. Mayer \& P. Alexander (Eds.), The Handbook of Research on Learning and Instruction (pp. 296-321). New York: Routledge Press.

Gadgil, S., Nokes-Malach, T. J., \& Chi, M. T. (2012). Effectiveness of holistic mental model confrontation in driving conceptual change. Learning and Instruction, 22(1), 47-61. doi:10.1016/j.learninstruc2011.06.002

Ginns, P., \& Leppink, J. (2019). Special issue on cognitive load theory: Editorial. Educational Psychology Review, 31, 255-259 doi:10.1007/s10648-019-09474-4

Hahs-Vaughn, D. (2017). Applied Multivariate Statistical Concepts. New York, NY: Routledge.

Hefter, M. H., \& Berthold, K. (2020). Preparing learners to self-explain video examples: Text or video introduction?. Computers in Human Behavior. Advanced online publication. doi:10.1016/j.chb.2020.106404

Hoogerheide, V., Deijkers, L., Loyens, S. M., Heijltjes, A., \& van Gog, T. (2016). Gaining from explaining: Learning improves from explaining to fictitious others on video, not from writing to them. Contemporary Educational Psychology, 44-45, 95-106. doi:10.1016/j.cedpsych.2016.02.005

Jonassen, D. H. (2000). Toward a design theory of problem solving. Educational Technology Research \& Development, 48(4), 63-85. doi:10.1007/BF02300500 
Kalyuga, S., Ayres, P., Chandler, P., \& Sweller, J. (2003). The expertise reversal effect. Educational Psychologist, 38(1), 23-31. doi:10.1207/S15326985EP3801_4

King, A. (1990). Enhancing peer interaction and learning in the classroom through reciprocal questioning. American Educational Research Journal, 27(4), 664-687. doi:10.3102/00028312027004664

Leppink, J., Broers, N. J., Imbos, T., van der Vleuten, C. P., \& Berger, M. P. (2012). Selfexplanation in the domain of statistics: an expertise reversal effect. Higher Education, 63(6), 771-785. doi:10.1007/s10734-011-9476-1

Lin, L., \& Atkinson, R. K. (2013). Enhancing learning from different visualizations by selfexplanation prompts. Journal of Educational Computing Research, 49(1), 83-110. doi:83-110. 10.2190/EC.49.1.d

Lin, L., Atkinson, R. K., Savenye, W. C., \& Nelson, B. C. (2016). Effects of visual cues and self-explanation prompts: empirical evidence in a multimedia environment. Interactive Learning Environments, 24(4), 799-813. doi:10.1080/10494820.2014.924531

Lombrozo, T. (2006). The structure and function of explanations. TRENDS in Cognitive Science, 10(10), 464-470. doi:10.1016/j. tics.2006.08.004

McCormick, R. (1997). Conceptual and procedural knowledge. International Journal of Technology and Design Education, 7(1-2), 141-159.

McEldoon, K. L., Durkin, K. L., \& Rittle-Johnson, B. (2013). Is self-explanation worth the time? A comparison to additional practice. British Journal of Educational Psychology, 83(4), 615-632. doi:10.1111/j.2044-8279.2012.02083.x

Miller-Cotto, D., \& Auxter, A. E. (2019). Testing the ecological validity of faded worked examples in algebra. Educational Psychology, 1-15. doi:10.1080/01443410.2019.1646411

Morrison, J. R., Bol, L., Ross, S. M., \& Watson, G. S. (2015). Paraphrasing and prediction with self-explanation as generative strategies for learning science principles in a simulation. Educational Technology Research and Development, 63(6), 861-882. doi:10.1007/s11423-015-9397-2

Neubrand, C., \& Harms, U. (2017). Tackling the difficulties in learning evolution: Effects of adaptive self-explanation prompts. Journal of Biological Education, 51(4), 336-348. doi:10.1080/00219266.2016.1233129

Nokes, T. J., Hausmann, R. G. M., VanLehn, K., \& Gershman, S. (2011). Testing the instructional fit hypothesis: The case of self-explanation prompts. Instructional Science, 39(5), 645-666. doi:10.1007/s11251-010-9151-4

O’Neil, H. F., Chung, G. K. W. K., Kerr, D., Vendlinski, T. P., Buschang, R. E., \& Mayer, R. E. (2014). Adding self-explanation prompts to an educational computer game. Computers in Human Behavior, 30, 23-28. doi:10.1016/j.chb.2013.07.025

Paas, F., \& Ayres, P. (2014). Cognitive load theory: A broader view on the role of memory in learning and education. Educational Psychology Review, 26(2), 191-195. doi:10.1007/s10648-014-9263-5

Paas, F., \& Van Merriënboer, J. J. G. (1994). Instructional control of cognitive load in the training of complex cognitive tasks. Educational Psychology Review, 6(4), 351-371. doi:10.1007/BF02213420

Rau, M. A., Aleven, V., \& Rummel, N. (2015). Successful learning with multiple graphical representations and self-explanation prompts. Journal of Educational Psychology, 107(1), 30-46. doi:10.1037/a0037211

Renkl, A. (2014). Toward an instructionally oriented theory of example-based learning. Cognitive Science, 38(1), 1-37. doi:10.1111/cogs.12086 
Renkl, A., \& Atkinson, R. K. (2003). Structuring the transition from example study to problem solving in cognitive skill acquisition: A cognitive load perspective. Educational Psychologist, 38(1), 15-22. doi:10.1207/S15326985EP3801_3

Renkl, A., \& Eitel, A. (2019). Self-explaining: Learning about principles and their application. In J. Dunlosky \& K. Rawson (Eds.), Cambridge Handbook of Cognition and Education (pp. 528-549). Cambridge University Press.

Rittle-Johnson, B., \& Loehr, A. M. (2017). Eliciting explanations: Constraints on when selfexplanation aids learning. Psychonomic Bulletin \& Review, 24(5), 1501-1510. doi:10.3758/s13423-016-1079-5

Rittle-Johnson, B., Loehr, A. M., \& Durkin, K. (2017). Promoting self-explanation to improve mathematics learning: A meta-analysis and instructional design principles. ZDM, 49(4), 599-611.

Rittle-Johnson, B., \& Schneider, M. (2015). Developing conceptual and procedural knowledge of mathematics. In R. C. Kadosh \& A. Dowker (Eds.), Oxford Handbook of Numerical Cognition (pp. 1102-1118). Oxford: Oxford University Press.

Roy, M., \& Chi, M. T. H. (2005). The self-explanation principle in multimedia learning. In R. Mayer (Ed.), Cambridge Handbook of Multimedia Learning (pp. 271-286). New York, NY: Cambridge University Press.

Si, J., Kim, D., \& Na, C. (2014). Adaptive instruction to learner expertise with bimodal process-oriented worked-out examples. Journal of Educational Technology $\mathcal{E}$ Society, 17(1), 259-271. Retrieved from http://www.jstor.org/stable/jeductech soci.17.1.259

Sweller, J., Ayres, P., \& Kalyuga, S. (2011). Cognitive load theory. New York: Springer.

Van Gog, T., Paas, F., \& Van Merriënboer, J. J. (2004). Process-oriented worked examples: Improving transfer performance through enhanced understanding. Instructional Science, 32(1), 83-98. doi:10.1023/B:TRUC.0000021810.70784.b0

Wang, Z., \& Adesope, O. (2017). Do focused self-explanation prompts overcome seductive details? A multimedia study. Journal of Educational Technology \& Society, 20(4), 4757. Retrieved from http://www.jstor: stable/26229204

Wittrock, M. C. (1989). Generative processes of comprehension. Educational Psychologist, 24(4), 345-376. doi:10.1207/s15326985ep2404_2

Wylie, R., \& Chi, M. T. H. (2014). The self-explanation principle in multimedia learning. In R. E. Mayer (Ed.), The Cambridge Handbook of Multimedia Learning (2nd ed., pp. 413-432). New York: Cambridge University Press.

Yeh, Y.-F., Chen, M.-C., Hung, P.-H., \& Hwang, G.-J. (2010). Optimal self-explanation prompt design in dynamic multi-representational learning environments. Computers \& Education, 54(4), 1089-1100. doi:10.1016/j.compedu.2009.10.013 